\title{
REPARAÇÃO DE FERIDAS CUTÂNEAS DE CAMUNGONGOS TRATADAS COM ÓLEO DE PIMENTA LONGA, Piper hispidinervum C.DC
}

\section{REPAIRING OF CUTANEOUS WOUNDS OF CAMUNGONGOS TREATED WITH OIL OF LONG PEPPER, Piper Hispidinervum C.DC}

\author{
Iara Moreira JARDIM
}

\begin{abstract}
RESUMO: A pimenta longa espécie Piper hispidinervum é uma piperácea da flora brasileira, encontrada no vale do
\end{abstract} Rio Acre. Do óleo essencial desta pimenta predomina o safrol com rendimento deste constituinte em até 5,5\% e teores entre $80 \%$ à $97 \%$ em relação ao peso da ramagem fina. A reconhecida ação inseticida e sinergística confere ao óleo desta pimenta longa alto valor comercial. Tratamentos de doenças venéreas, desordens intestinais, males genito-urinário e cura de reumatismo também foram registrados através de relatos populares. O objetivo deste trabalho foi averiguar a resposta tecidual promovida pela atividade do óleo da Piper hipidinervum, ocorrida em feridas cutâneas de camundongos da espécie Swiss albinus após aplicações diárias de pomada veiculada ao óleo essencial, nas concentrações deste composto em 1,25\%, 2,5\% e 5\%, durante os períodos de quatro, oito e doze dias. O óleo essencial utilizado neste experimento, foi adquirido através de produtor rural, município de Rio Branco estado do Acre, obtido por extração de pimenta longa, espécie Piper hispidinervum, sendo o beneficiamento realizado por meio de arraste de vapor, processo padrão da EMBRAPA/AC, que orienta a produção na região. Durante o tratamento as feridas foram observadas para análise macroscópica, considerando os eventos básicos do processo de reparo em tecido animal "in vivo”. O material de análise, objeto desse estudo, após procedimento cirúrgico, foi acondicionado em solução de formol a $10 \%$, as peças foram seccionadas transversalmente, desidratadas em álccol, diafanizadas em xilol e incluídas em parafina sob a forma de blocos, submetido a microtomia e obtidos cortes de cinco micras de espessura, sendo corado por solução de hematoxilina-eosina(HE). A análise histológica baseou-se nas respostas teciduais: espessamento da crosta, infiltrado inflamatório mononuclear e polimorfonuclear, reepitelização, vasodilatação e hiperemia, edema e fibrosamento, em graus de intensidade: ausente, discreto, moderado e intenso, comparados ao grupo controle, sendo esses avaliados qualitativamente. Os resultados alcançados, resposta tecidual de feridas cutâneas de camundongos revelaram que a proliferação epitelial foi superior ao grupo controle inferindo-se que o material é pode ser capaz de acelerar o processo de reparação tecidual em camundongos, embora o tempo não fosse suficiente para uma avaliação da reparação tecidual completa. Do $8^{\circ} \mathrm{e}$, mais acentuadamente no $12^{\circ}$ dia, os resultados revelaram características de regressão quanto ao reparo das feridas.

Palavras-chave: pimenta longa, safrol, ferida, reparação tecidual, cicatrização

ABSTRACT: The pepper long species Piper hispidinervum is a piperácea of the Brazilian flora, found in it is worth him/it of Rio Acre. Of the essential oil of this pepper the safrol prevails with income of this constituent one in to 5,5\%

\footnotetext{
${ }^{1}$ Mestre em Biotecnologia (UninCor). Especialista em Gestão Ambiental (PUC Minas). Especialista em Trabalho e Negociação - Qualificação de Gestores (PUC Minas) . Graduada em Ciências Biológicas (Instituto Metodista de Minas Gerais). E-mail: direcaobetim@unincor.edu.br
} 
and tenors among $80 \%$ to the $97 \%$ in relation to the weight of the foliage dies. Recognized it insecticide and synergistic action checks to the oil of this long pepper loud commercial value. Treatments of venereal diseases, intestinal disorders, genito-urinary evils and cure of rheumatism were also registered through popular reports. The objective of this work was to discover the tissue's answer promoted by the activity of the oil of the Piper hipidinervum, happened in cutaneous wounds of mice of the species Swiss albinus after daily applications of ointment transmitted to the essential oil, in the concentrations of this composed in $1,25 \%, 2,5 \%$ and $5 \%$, during the periods of four, eight and twelve days. The essential oil used in this experiment, it was acquired through rural producer, municipal district of Rio Branco of Acre, obtained by extraction of long pepper, species Piper hispidinervum, being the improvement accomplished through it drags of steam, standard process of EMBRAPA/AC, that guides the production in the area. During the treatment the wounds were observed for macroscopic analysis, considering the basic events of the repair process in fabric animal "alive in." The analysis material, object of that study, after surgical procedure, it was conditioned in formol solution to $10 \%$, the pieces were split up obliquely, dehydrated in alcohool diafanized in xylol and included in paraffin under the form of blocks, submitted the microtomy and obtained cuts of five micras of thickness, being colored by hematoxilineosin(HE solution). The histological analysis based on the answers teciduais: espessamento of the crust, infiltrated inflammatory mononuclear and polimorfocoreus, reepitelizement, vasodilatation and hiperemia, edema and fibrosament, in intensity degrees: it is absent, discreet, moderate and intense, compared to the group controls, being those evaluated qualitatively. The reached results, tissue's answer of cutaneous wounds of mice revealed that the proliferation epitelial was superior to the group it controls being ended that the material is apparently capable of accelerating the process of tissue's repairing in mice, although the time was not enough for an evaluation of the tissue's repairing completes. Of the 8th and, more strongly in the 12 nd day the results revealed regression characteristics as for the repair of the wounds.

Keywords: pepper long, safrol, wound, tissue repair, wound healing

\section{INTRODUÇÃO}

\section{A espécie Piper hispidinervum,} conhecida por pimenta longa, foi catalogada na década de 80 e desde então vêm despertando grande interesse em indústrias nacionais e estrangeiras devido ao alto teor de safrol encontrado, correspondendo até $97 \%$ do óleo essencial total, contido principalmente nas folhas e ramos da parte aérea (GOTTLIEB et al.,1981)

\section{A espécie Piper hispidinervum} apresenta arbusto ramificado, nodoso, com aproximadamente cinco metros de altura, pedúnculo espesso e folhas obloncolanceoladas. Esta espécie produz um óleo essencial rico em safrol de alto valor comercial, com rendimento deste constituinte em até $5,5 \%$ e teores entre $80 \%$ à $97 \%$ em relação ao peso da ramagem fina (CORREA,1994).

O safrol é um fenilpropanóide, com reconhecida ação antiinflamatória e sinergística, sendo também comprovada a sua atividade carcinogênica "in vitro". È de grande importância científica-tecnológica como precursor de uma variedade de compostos, notadamnete, fármacos, 
bioinseticidas biodegradáveis, fixadores de aroma e, mais recentimente de drogas antitrombóticas e auxinas endólicas (CORREA,1994)

O óleo essencial, extraído da Piper hispidinervum, é produto do metabolismo secundário da planta e está sujeito à variação quantitativa em relação a sua distribuição no vegetal, comprovadamente com a maior quantidade nas folhas e ramos finos.

Em vista dos fatos, investigar o óleo de pimenta longa, matéria prima abundante e predominantemente brasileira como possibilidade de emprego para novos fármacos de interesse terapêutico e também em substituição daqueles usualmente utilizados no mercado, constitui-se em um trabalho promissor potencializando áreas de interesse ambiental, econômico e social.

O trabalho teve por objetivo avaliar a resposta tecidual após aplicação tópica em feridas na pele de camundongo, que baseou em aplicações do óleo essencial da pimenta longa, veiculado em pomadas aplicadas diariamente em feridas provocadas em tecido vivo. A evolução histológica das lesões foram analisadas considerado as variantes tempo de aplicação e concentração do extrato

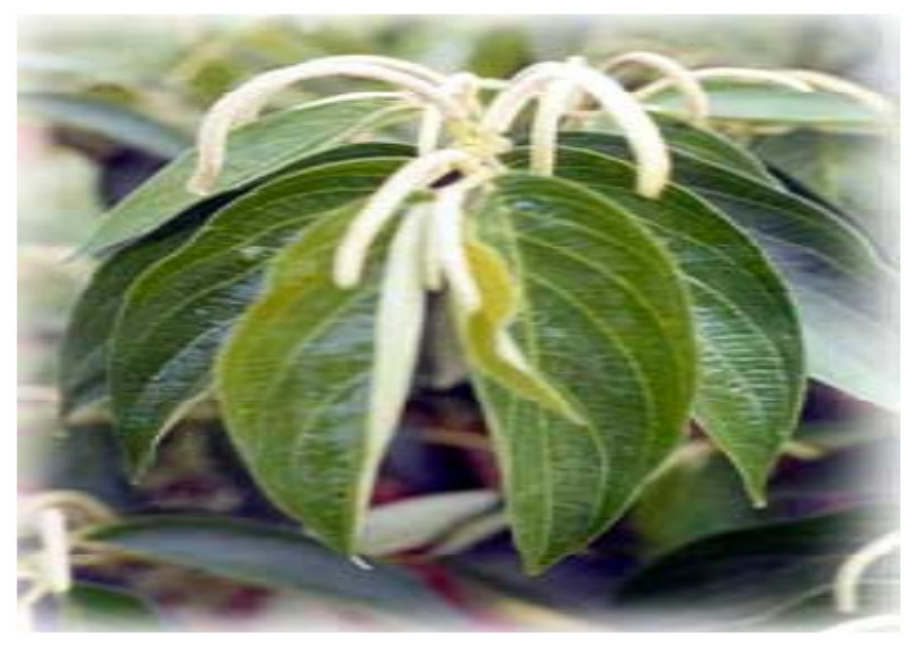

FIGURA 1 - Detalhe das folhas e da inflorescência da espécie Piper hispidinervum. Cultivo da espécie por produtor rural em Senador Guilmar, município de Rio Branco no estado do Acre, subsidiado pela EMBRAPA, AC RE 2001. 


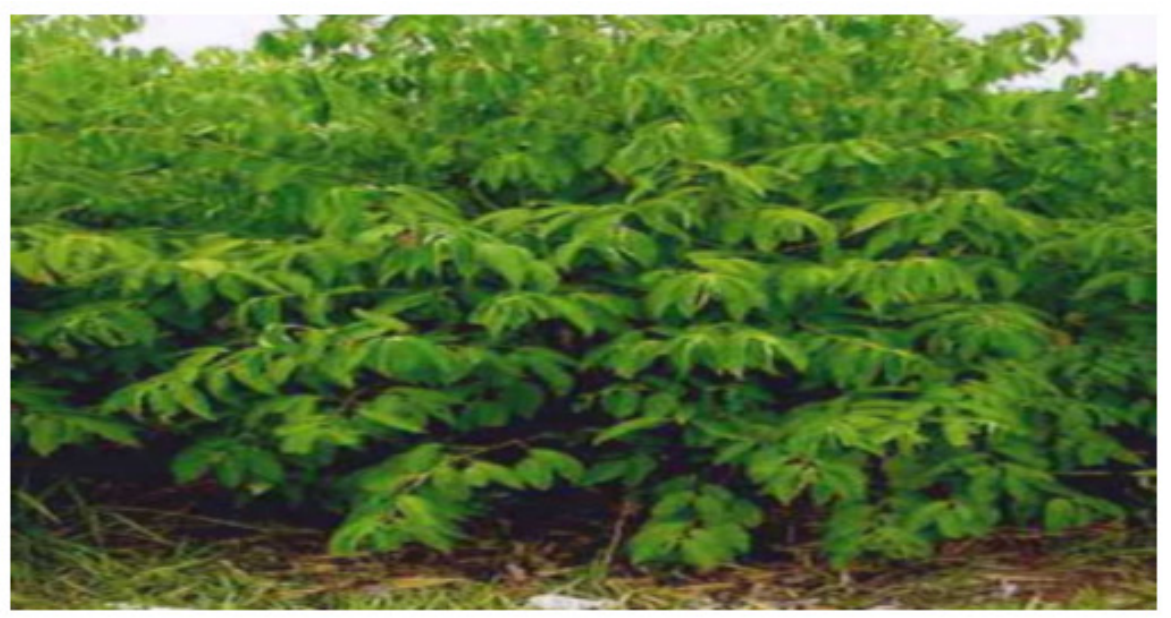

FIGURA 2 - Planta adulta, espécie Piper hispidinervum. EMBRAPA- Rio Branco, ACRE, 2001.

\section{DESENVOLVIMENTO}

\subsection{Aquisição do óleo essencial de Pimenta} longa, espécie Piper hispidinervum.

O óleo essencial de pimenta longa, espécie Piper hispidinervum, utilizado neste experimento foi adquirido através de produtor rural em Senador Guilmar, município de Rio Branco- Acre.

O óleo essencial foi obtido por extração de pimenta longa, espécie Piper hispidinervum, tendo as plantas aproximadamente $1 \mathrm{~m}$ de diâmetro de copa e altura de $1,70 \mathrm{~m}$, quando cortadas distando 40 $\mathrm{cm}$ do solo. As folhas e ramos foram colocados em secador solar, com cobertura plástica transparente por um período de cinco dias. Para evitar a fermentação, durante o processo de secagem, efetuou-se a revirada por duas vezes ao dia. O beneficiamento foi realizado por meio de arraste de vapor, utilizando sistema de caldeira acoplada a um extrator. $\mathrm{O}$ óleo foi filtrado e armazenado em tambores de aço revestidos com epóxi, para posterior comercialização. Este processo é padrão da EMBRAPA que orienta a produção na região. (PIMENTEL et al., 2000)

\subsection{Preparo da pasta do óleo essencial de}

\section{Pimenta Longa}

O veículo contendo o óleo essencial de pimenta longa foi elaborado em 22/10/05 no laboratório de farmácia da UNINCOR utilizando $660 \mathrm{~g}$ de vaselina, $240 \mathrm{~g}$ de lanolina e 0,16 g de BHT para $800 \mathrm{~g}$ de base. O percentual do óleo essencial de pimenta longa utilizado na elaboração das quatro diferentes concentrações estão descritas na TABELA 1. 
TABELA 1 - Concentrações do óleo essencial de pimenta longa na elaboração da pasta para aplicação

\begin{tabular}{ccc}
\hline $\begin{array}{c}\text { Identificação dosTipos das } \\
\text { pastas }\end{array}$ & $\begin{array}{c}\text { Porcentagem do composto } \\
\text { óleo de pimenta longa }\end{array}$ & $\begin{array}{c}\text { Porcentagem do } \\
\text { Veículo }\end{array}$ \\
\hline Pasta 01 & $0 \%$ & $100 \%$ \\
Pasta 02 & $1,25 \%$ & $98,75 \%$ \\
Pasta 03 & $2,5 \%$ & $97,5 \%$ \\
Pasta 04 & $5 \%$ & $95 \%$ \\
\hline
\end{tabular}

As pomadas foram armazenadas em

potes de cor preta, hermeticamente fechados e etiquetados com as descrições de

concentração de cada composto.

\subsection{Caracterização do tipo de ferida e material de estudo}

Para estudo e análises da resposta tecidual, considerando atividade do óleo de pimenta longa, foram utilizados trinta e seis camundongos da espécie Swiss albinus, machos, adultos, pesando em média 50 gramas, adquiridos no biotério da Universidade Federal de Minas GeraisUFMG.

O experimento teve início em 22 de setembro, quando os animais nascidos em 31/07/05 foram transportados até o biotério da Universidade Vale do Rio Verde de Três Corações -UNINCOR Campus Três Corações, observando ventilação e hidratação durante o trajeto. No biotério da Unincor os animais foram alojados em gaiolas individuais para aclimatação e crescimento. Durante todo o período do experimento receberam ração marca Nubilab e água diariamente.
Decorridos 36 dias de alojamento individual e tendo atingido peso de 50 gramas e 90 dias de nascido, os camundongos foram submetidos aos procedimentos cirúrgicos para obstrução e corte, provocando uma ferida de $8 \mathrm{~mm}$ de diâmetro.

Os animais foram anestesiados com quetamina e xilasina, com dosagens de $0,5 \mathrm{ml}$ e $0,1 \mathrm{ml}$ para cada $50 \mathrm{~g}$ de peso, respectivamente (NASSRI, 2002).

Sob efeito anestésico, procedeu-se a depelação do local a ser ferido e a antissepsia com PVPI.

Em cada animal foram feitas duas incisões e excisões, de $8 \mathrm{~mm}$ de diâmetro, na parte dorsal, utilizando para difusão do tecido o aparelho Punch (Trepano) no 08 Marca Richter, indicado para cortes cirúrgicos específicos. Foi observado a regularidade do diâmetro e a profundidade do corte, de modo a atingir o tecido vascularizado, e não o tecido muscular.

As feridas cutâneas provocadas nos camundongos, nomeadas por segunda intenção, apresentaram eventos particulares e 
diferenciados, sendo a caracterização dessa ferida uma reação inflamatória mais intensa, decorrente de grande perda de células e tecidos, o que exige recomposição da arquitetura original removida pelo procedimento (ROBBINS, 1991).

A fim de evitar a contaminação, os animais permaneceram alojados em gaiolas individuais para recuperação, recebendo ração, água e duas aplicações da pasta, diariamente (SHUKA et al., 1998).

A aplicação da pasta foi realizada, individualmente, duas vezes ao dia, utilizando pincel de cerdas plásticas. $\mathrm{O}$ experimento foi conduzido em blocos casualizados, em esquema fatorial, sendo $3 X 3 X+1$, ou seja, 3 épocas, 3 concentrações e 1 grupo controle, divididos em três grupos, de acordo com seu tempo experimental, em períodos de 4, 8 e 12 dias, na seguinte condição:

Cada grupo foi subdividido em três subgrupos, na seguinte condição:Grupo A A1, A2, A3 e A4, assim sucessivamente de acordo com as concentrações e tempo experimental. Os grupos controle foram sempre A1, B1 e C1 analisado nos períodos acima descritos.Todos os eventos experimento foram do seguidos, conforme TABELA

TABELA 2 - Distribuição de grupos por evento.

\begin{tabular}{|c|c|c|c|c|}
\hline Grupos & $\begin{array}{l}\text { Concentrações do Óleo } \\
\text { Essencial na pasta }\end{array}$ & $\begin{array}{l}\text { Número de Animais } \\
\text { Sacrificados por } \\
\text { período }\end{array}$ & $\begin{array}{l}\text { Períodos } \\
\text { em Dias }\end{array}$ & $\begin{array}{c}\text { Data da Coleta } \\
\text { do material a } \\
\text { ser estudado }\end{array}$ \\
\hline \multirow[t]{3}{*}{1} & $0 \%$ & 3 & 1 a 4 & $01 / 11 / 05$ \\
\hline & & & 5 a 8 & $05 / 11 / 05$ \\
\hline & & & 9 a 12 & 09/11/05 \\
\hline \multirow[t]{3}{*}{2} & $1,25 \%$ & 3 & 1 a 4 & 01/11/05 \\
\hline & & & 5 a 8 & $05 / 11 / 05$ \\
\hline & & & 9 a 12 & 09/11/05 \\
\hline \multirow[t]{3}{*}{3} & $2,5 \%$ & 3 & 1 a 4 & $01 / 11 / 05$ \\
\hline & & & 5 a 8 & $05 / 11 / 05$ \\
\hline & & & 9 a 12 & 09/11/05 \\
\hline \multirow[t]{3}{*}{4} & $5 \%$ & 3 & 1 a 4 & $01 / 11 / 05$ \\
\hline & & & 5 a 8 & 05/11/05 \\
\hline & & & 9 a 12 & 09/11/05 \\
\hline
\end{tabular}


Decorrido o tempo proposto para aplicação da pasta em cada grupo experimental e certificado a identificação de cada grupo, os camundongos receberam superdosagem anestésica com inalação de éter etílico, provocando a morte do animal.

A região dorsal do animal foi tricomizada e a área da ferida dissecada. Os cortes macroscópicos do tecido abrangeram suficiente tecido normal circunjacente como pode ser acompanhado na seqüência da FIGURA 5.

Após a remoção dos tecidos, esses foram acondicionados em solução de formol a $10 \%$, em recipientes unitários e identificados por um período mínimo de 48 horas. Decorrido o período de fixação, as peças foram seccionadas transversalmente, desidratadas em álccol, diafanizadas em xilol e incluídas em parafina sob a forma de blocos, posteriormente o material foi submetido a microtomia e obtidos cortes de cinco micras de espessura, sendo corado por solução de hematoxilina-eosina(HE). De cada animal foi confeccionada duas lâminas, sendo uma para cada corte.

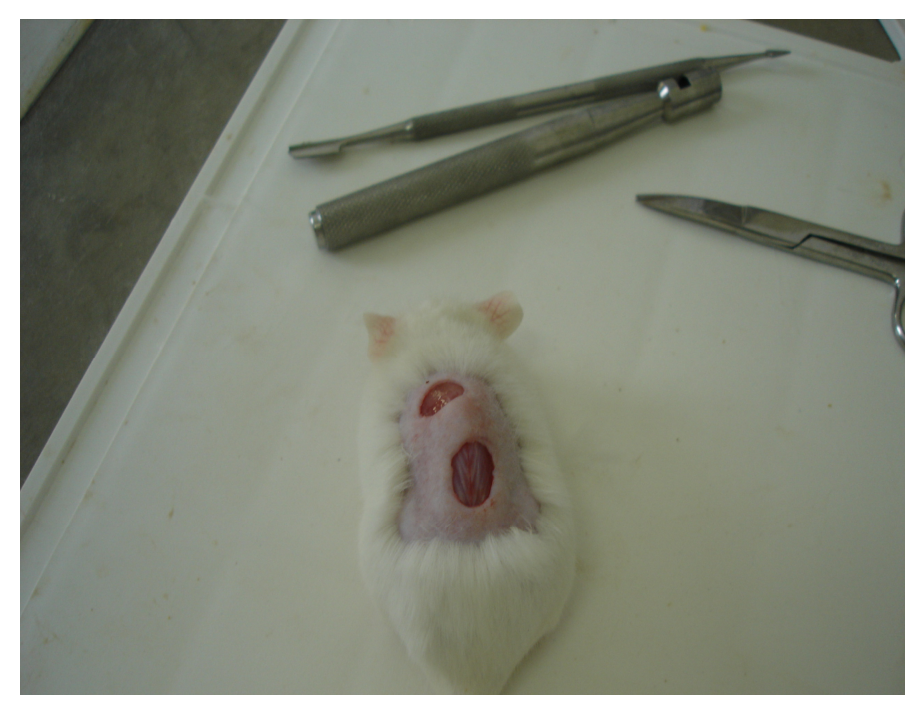

FIGURA 3 - Incisão e corte efetuados no dorso do camundongo, utilizando os instrumentos cirúrgicos: punch $\mathrm{n}^{\mathrm{o}} 08$, tesoura de ponta, pinça e espátula, observando o diâmetro e profundidade uniforme do corte. Biotério da UninCor, Campus Três Corações. 

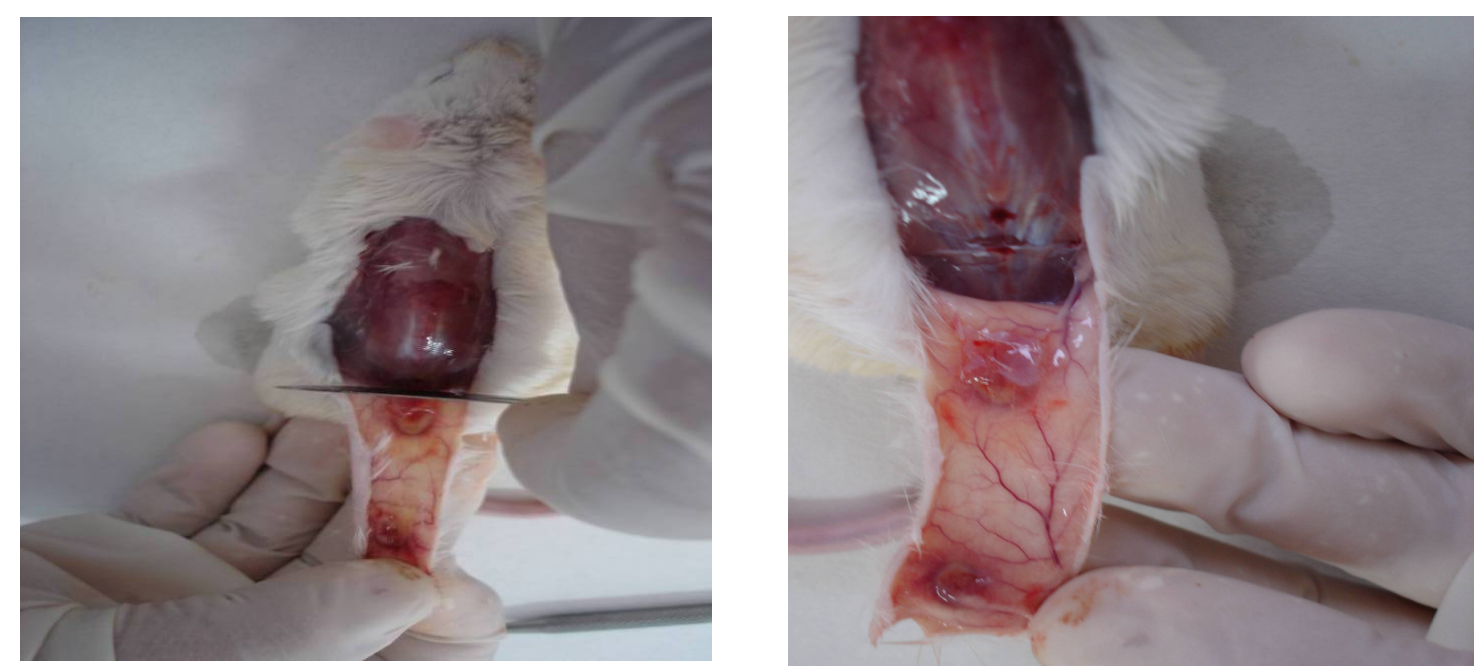

FIGURA 4 - Procedimento cirúrgico - corte da área lesada com retirada da porção do tecido tratado (A).Vasos sanguíneos e porção interna do tecido tratado(B). Laboratório de Patologia da UninCor, Campus Três Corações.

\subsection{Interpretação do material de estudo}

Durante o tratamento foram

\section{RESULTADOS}

observados os eventos para análise macroscópico, através de observação e registro fotográfico, levando em consideração os eventos básicos do processo de inflamação em tecido vivo animal.

A análise histológica baseou-se nas respostas teciduais apresentadas, comparando os eventos ocorridos nos animais controle e nos tratados com a pomada em concentrações especificadas no item 4.2 em materiais e métodos. Foram avaliados qualitativamente os eventos básicos histopatológicos: espessamento da crosta, infiltrado inflamatório mononuclear e polimorfonuclear, reepitelização, vasodilatação e hiperemia, edema e fibrosamento em graus de intensidade, sendo eles: ausente, leveou discreto, moderado e intenso (JUNQUEIRA, 2004) 
Ao exame macroscópico verificou-se que os animais do grupo A2 apresentavam crosta sem umidade, vasodilatação e edema característico do tipo de ferida em relação ao tempo de PO. Nos animais do grupo B2 o edema ainda estava presente em alguns animais, verificou-se a borda irregular e diferenciada quanto ao tamanho nos animais desse grupo. O grupo C2 caracterizou-se por apresentar feridas, aparentemente, curadas.

Os animais do grupo tratado A3 apresentaram bordas e área da ferida aumentada de volume, de aspecto irregular e formação de crosta úmida. Nos animais do grupo B3 a crosta estava presente de forma menos irregular em relação ao $4^{\circ}$ dia de PO. Ao exame dos animais do grupo C3 verificouse bordas e área central bem diminuídas de volume e crostas de coloração amarronzadas e não encontravam-se reparadas.

Os animais do grupo tratado A4 apresentaram feridas com borda aumentada de volume com formação de crosta de coloração marron claro. Nos animais do grupo B4 o edema ainda estava presente em alguns animais e em menor intensidade, a crosta estava presente de forma bem acentuada e aparentemente desprendida do tecido. Os animais do grupo $\mathrm{C} 4$ aparesentavam feridas com crosta e diferenciadas quanto ao tamanho da borda.

\subsection{Respostas teciduais obtidas no controle}

Ao exame microscópico das feridas no grupo controle após quatro dias de PO notou- se o edema, a vasodilatação e hiperemia característicos e também descritos por Robbins (1991), quanto ao tipo de cicatrização. Acompanhando a esse processo a presença da infiltrado inflamatório constituído de polimorfonuicleares e monunucleares sendo que este último em quantidade maior. A crosta apresentou-se em acentuada proliferação.

$\mathrm{O}$ animais do grupo controle no $8^{\circ}$ dia de PO demonstraram claramente a continuidade do processo de regeneração com a redução do edema, da vasodilatação e a continuidade da ação dos macrófagos, em predominância aos polimorfonucleares. A crosta apresentou-se desenvolvida, de forma menos espessa em relação ao grupo controle de 4 dias.

No $12^{\circ}$ dia o grupo controle apresentou resposta tecidual caracterizada pelo desaparecimento do edema, da vasodilatação e hiperemia, e do infiltrado de polimorfonucleares. Percebeu-se moderado infiltrado mononuclear e discreta reepitelização e fibrosamento, ambos na mesma intensidade.

\subsection{Respostas teciduais no tratamento de} $1,25 \%$ da concentração do Óleo de Pimenta Longa, nos tempos de 4, 8 e 12 dias

Ao exame microscópico, no $4^{\mathrm{o}}$ dia verificou-se acentuado desenvolvimento da crosta, acompanhado de edema, vasodilatação 
e hiperemia. O infiltrado com predominância de células mononucleadas, notou-se moderada reepitelização e discreto fibrosamento.

No $8^{\circ}$ dia encontrou-se reduzida espessura da crosta e intensidade do edema. Houve regressão na vasodilatação e hiperemia, intensificado infiltrado inflamatório mononuclear, em relação ao grupo com quatro dias de tratamento e mesma concentração. Registrou-se aparente desenvolvimento de reepitelização e fibrosamento.

No $12^{\circ}$ dia percebeu-se que o edema e o infiltrado inflamatório se mantiveram nas proporções do período de oito dias com uma discreta melhora no quadro de reepitalização e formação de crosta

\subsection{Respostas Teciduais obtidas no} Tratamento dado pela Concentração de 2,5\% do Óleo de Pimenta Longa, nos tempos de 4,8 e 12 dias

Ao exame microscópico, no $4^{\circ}$ dia de tratamento notou-se uma crosta em presença de discreta formação de edema, moderada vasodilatação e hiperemia. O com infiltrado predominantemente de células mononucleares. $\mathrm{O}$ processo de reepitalização estava presente com pequeno teor de fibrosamento.

$$
\text { No } 8^{\circ} \text { dia percebeu-se o }
$$
desaparecimento do edema e infiltrado leucocitário. Intensifica a vasodilatação, a hiperemia e o infiltrado inflamatório com células mononucleares. A crosta reduz a espessura e acompanha a intensificação do processo de reepitalização com aparecimento do fibrosamento.

No $12^{\circ}$ dia os eventos mencionados retrocedem em relação à cura e encontra-se o reaparecimento do edema e do infiltrado leucocitário e de células mononucleadas. A hiperemia e a vadilatação permanecem acompanhando a formação de crosta e ausência de fibrosamento.

\subsection{Respostas Teciduais obtidas no} Tratamento dado pela Concentração de 5,0\% do Óleo de Pimenta Longa, nos tempos de 4, 8 e 12 dias.

Ao exame microscópico, no $4^{\circ}$ dia formou-se crosta de espessura significativa, acompanhada de edema, vasodilatação, hiperemia, infiltrado inflamatório e reeepitelização nas mesmas proporções.

No $8^{\circ}$ dia notou-se discreto edemaciamento com vasodilatação e hiperemia. Intensificou o infiltrado inflamatório mononuclear e percebeu-se a ausência dos polimorfonucleares. A reepitalização e fibrosamento demonstravam-se aparentemente iguais em realação ao $4^{\circ}$ dia de tratamento.

No $12^{\circ}$ dia reintegra-se o edema e a vasodilatação, na ausência de polimorfonucleares, mantendo a crosta, o 
infiltrado inflamatório mononuclear conforme o período anteriormente observado. Houve discreta evolução da reepitalização e fibrosamento .

Através de análise estatística os dados foram processados considerando o tempo de tratamento em relação ao percentual da concentração do óleo de pimenta longa, Piper hispidinervum. Os resultados elaborados estão dispostos nas FIGURAS de $05 ` a 12$.

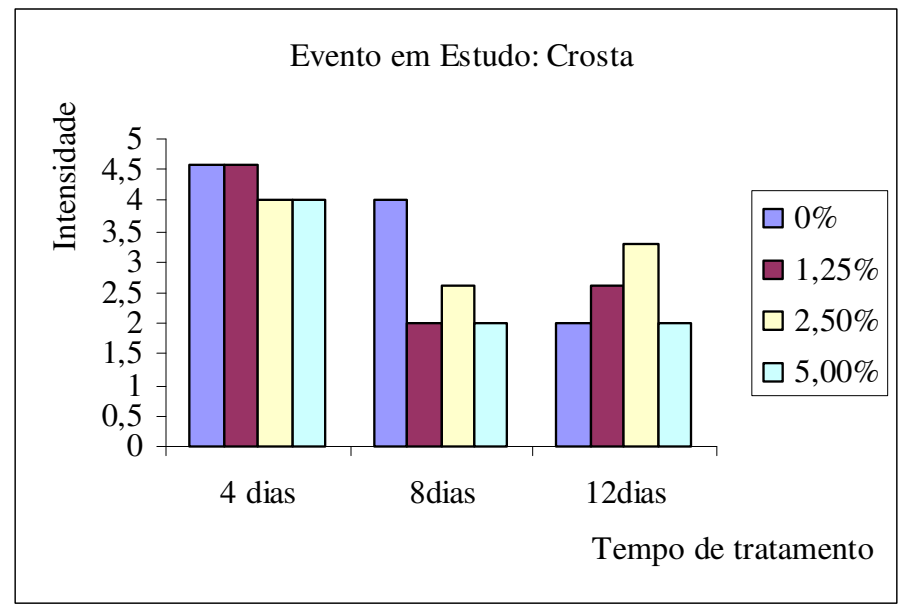

FIGURA 5 - Representação gráfica da média observada na área de ferida de camundongos dos grupos controle e tratados nas concentrações de $0 \%, 1,25 \%, 2,5 \%$, e $5 \%$ nos dias 4, 8 e 12 dias, considerando o evento crosta.

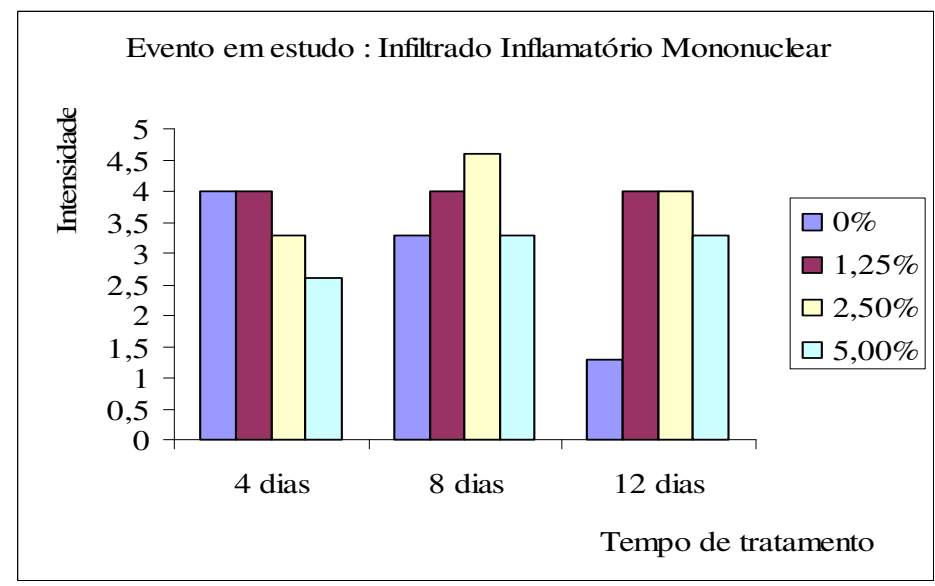

FIGURA 6 - Representação gráfica da média observada na área de ferida de camundongos dos grupos controle e tratados nas concentrações de $0 \%, 1,25 \%, 2,5 \%$, e $5 \%$ nos dias 4,8 e 12 dias, considerando o evento infiltrado inflamatório mononuclear. 


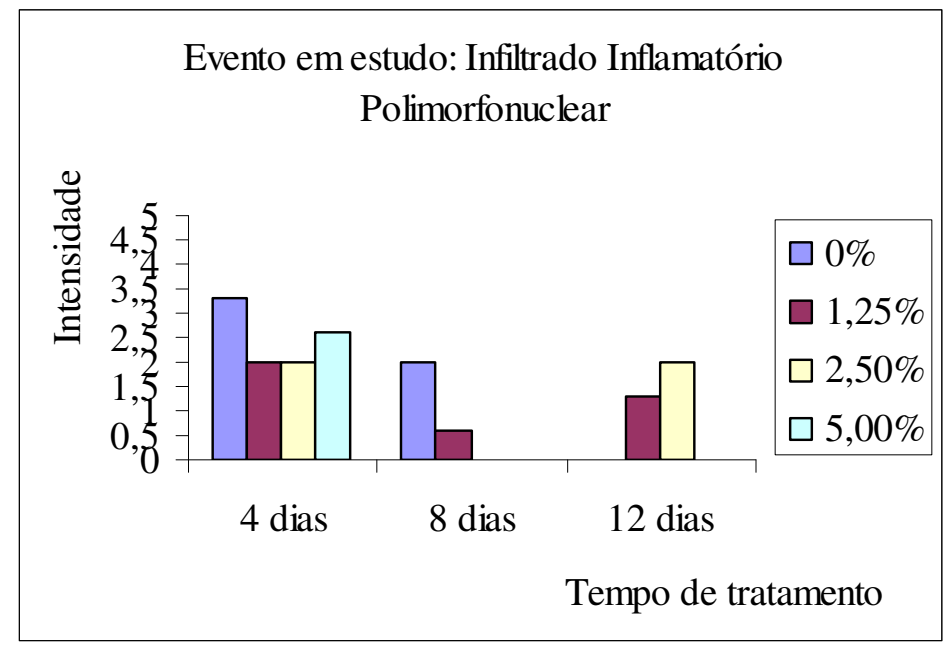

FIGURA 7 - Representação gráfica da média observada na área de ferida de camundongos dos grupos controle e tratados nas concentrações de $0 \%, 1,25 \%, 2,5 \%$, e $5 \%$ nos dias 4,8 e 12 do PO, considerando o evento infiltrado inflamatório polimorfonuclear.

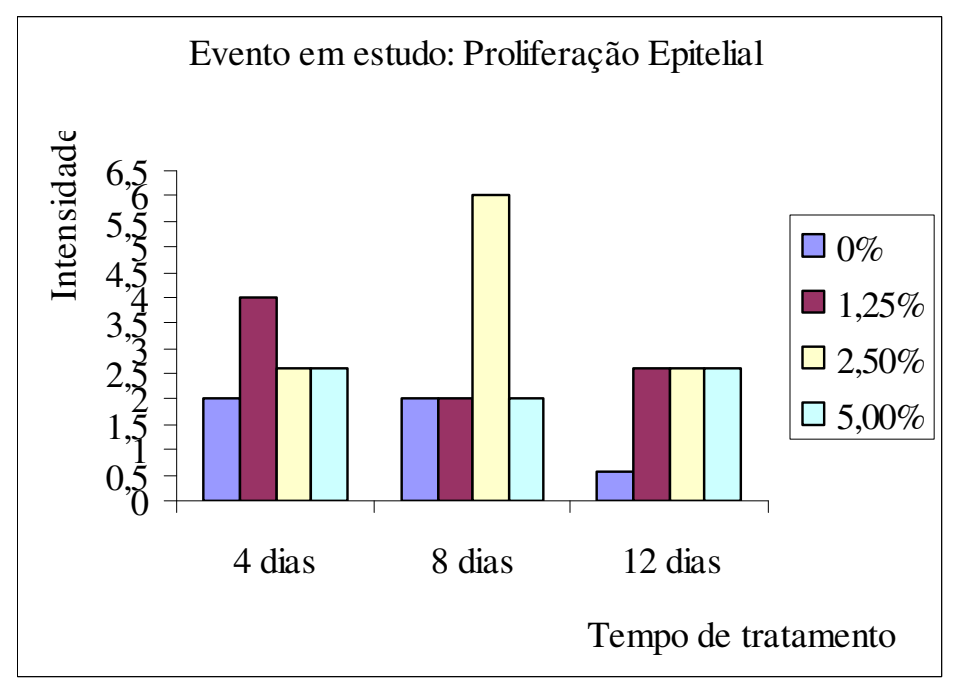

FIGURA 8 - Representação gráfica da média observada na área de ferida de camundongos dos grupos controle e tratados nas concentrações de $0 \%, 1,25 \%, 2,5 \%$, e $5 \%$ nos dias 4,8 e 12 dias, considerando o evento proliferação epitelial.

No presente trabalho, procurou-se identificar os eventos decorrentes da resposta tecidual apresentada nos grupos controle e grupos tratado, observando as micrografias elaboradas a partir do material de estudo, os quais estão relacionados nas FIGURAS 09 à 11 , com seus respectivos resultados. 


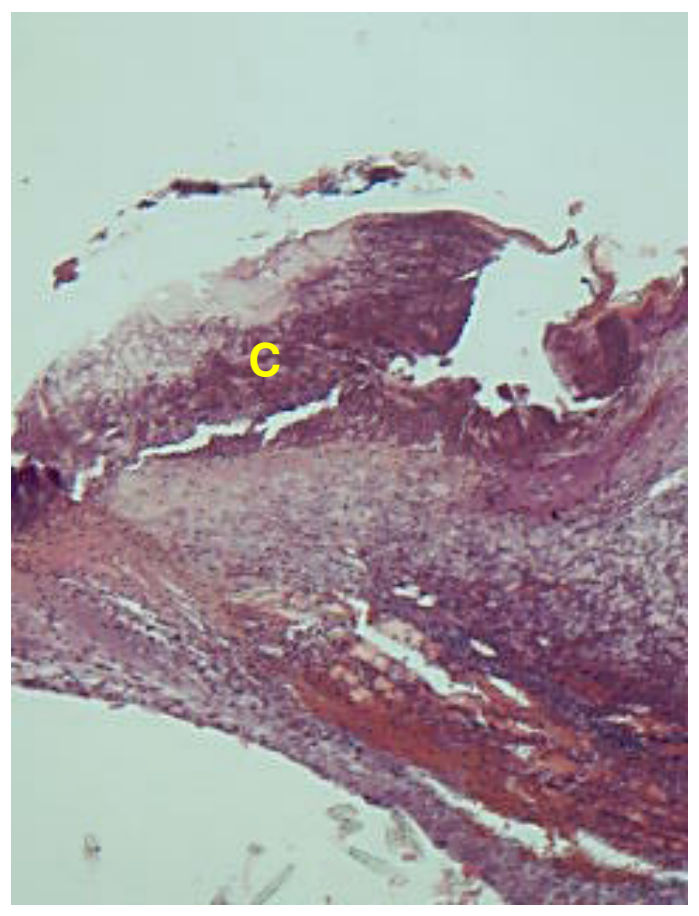

A

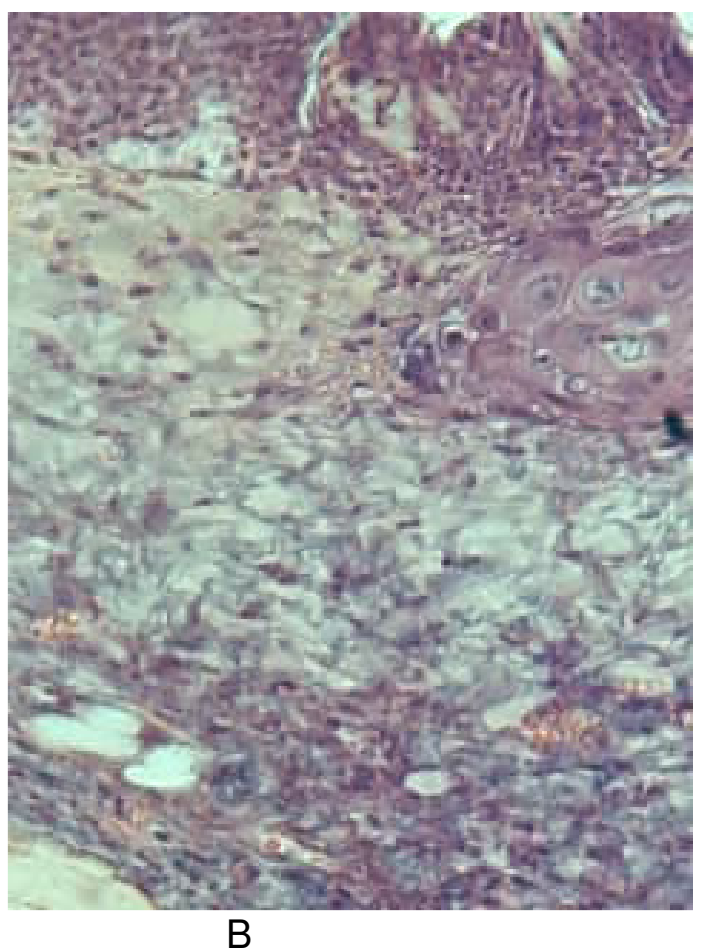

FIGURA 09 (4 A3) - Nota-se crosta (C) fina recobrindo tecido conjuntivo de pequena espessura e com moderado infiltrado inflamatório PMN e MN (ii). Coloração em HE. A - objetiva 10x; B objetiva $40 \mathrm{x}$ 


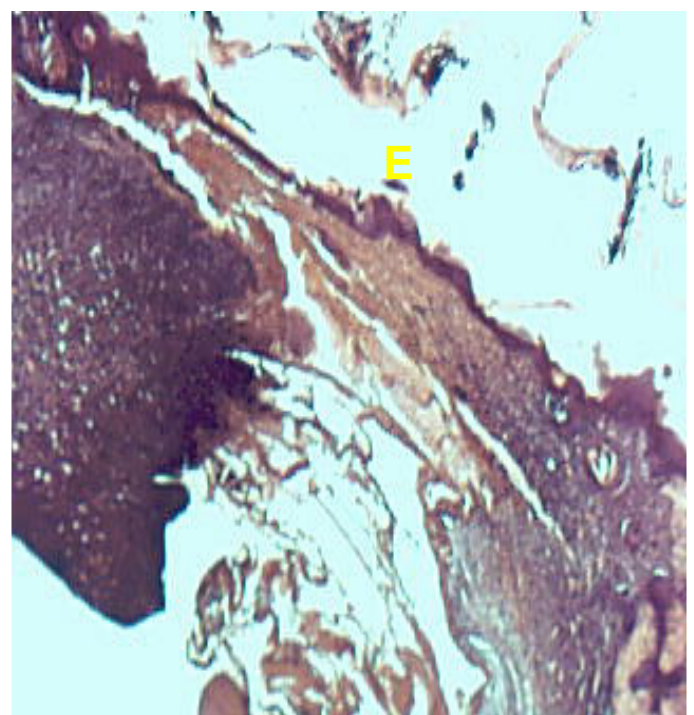

A

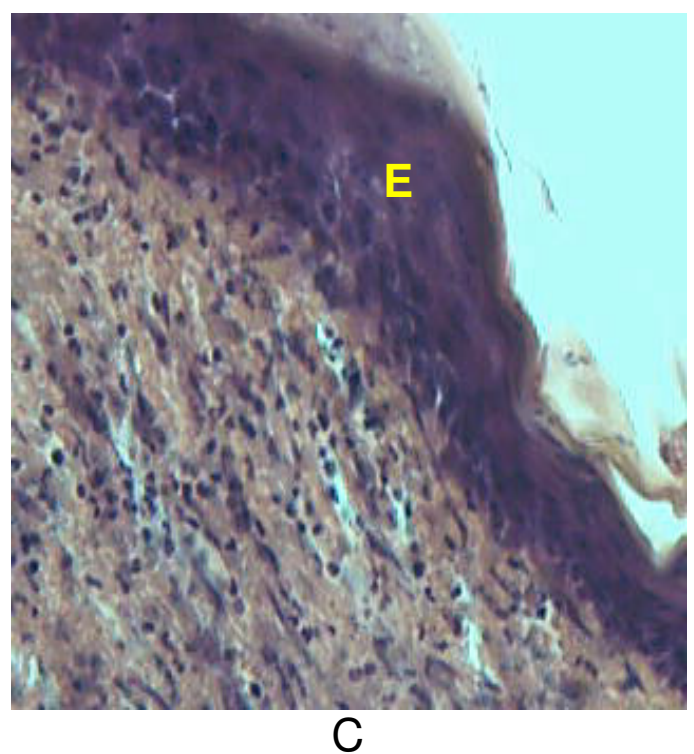

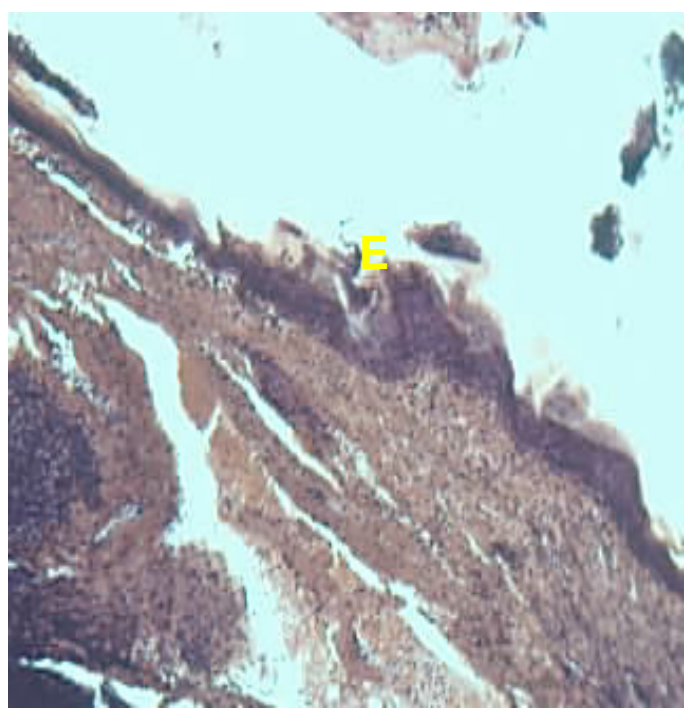

$\mathrm{B}$

FIGURA 10 (8 B3) - Nota-se epitélio (E) fino recobrindo tecido conjuntivo (TC) com discreto infiltrado inflamatório MN (ii). Coloração em HE. A - objetiva 4x; B - objetiva 10x, C - objetiva $40 x$ 


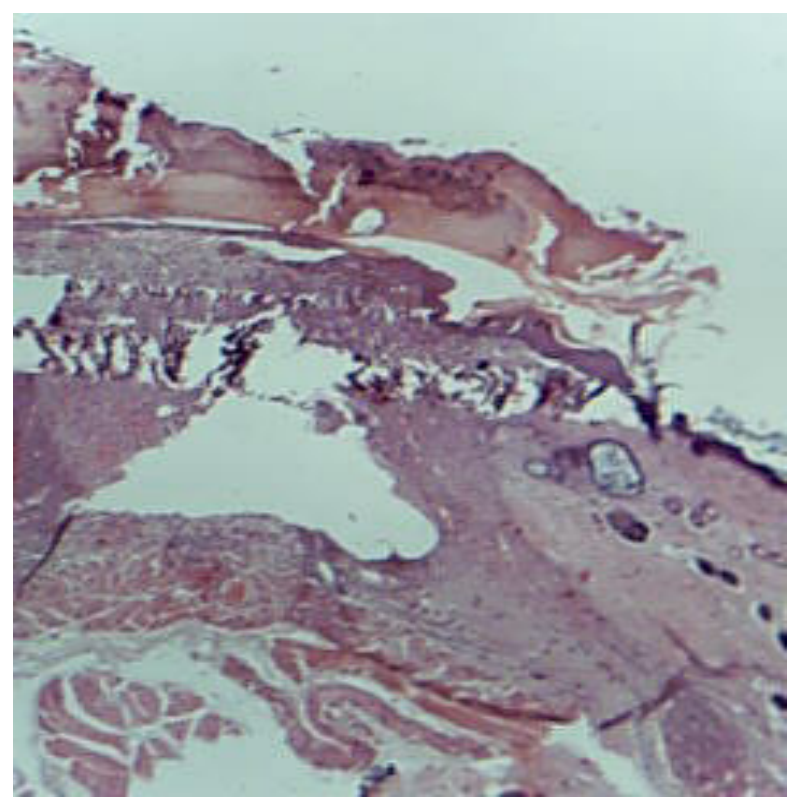

A

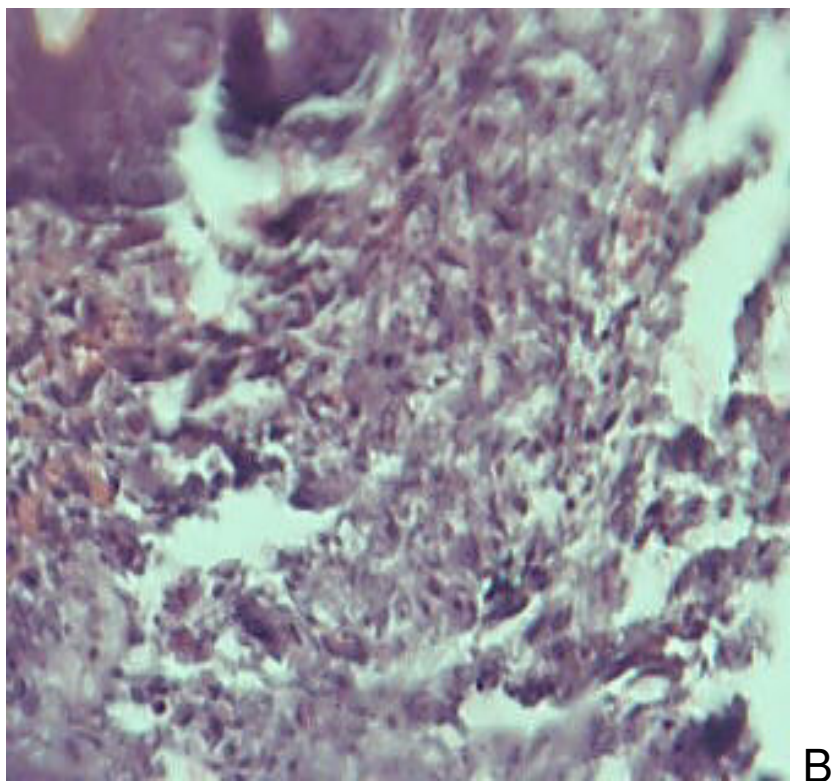

FIGURA 11 (12 C3) - Nota-se crosta (C) recobrindo tecido conjuntivo (TC) com moderado infiltrado inflamatório MN (ii). Nota-discreta proliferação epitelial. Coloração em HE. A - objetiva $4 \mathrm{x} ; \mathrm{B}$ - objetiva 10x 
Nos resultados apontados, verificou-se que o aumento de volume da área central e o aspecto irregular das feridas dos animais do grupo A3, foi devido a presença de crosta fibrino leucocitária, coincidindo com as observações feitas por Balbino et al.(2005). Uma ferida ao sofrer agressões é isolada do meio ambiente após ser preenchida por coágulos, fibrinas e exsudato, formando uma crosta.

Segundo Barbudo (2001), a presença de líquidos em ferimentos interfere no processo de crescimento bacteriano, dificulta a formação de tecido de granulação e reepitalização. Os fluidos em feridas interferem negativamente na contração cicatricial. Estes fatos foram coerentes com os resultados apresentados no B3, embora o tempo experimental não favorecesse a reparação tecidual completa.

Para Balbino et al.(2005) ausência de secreção purulenta e redução de umidade promovem a cicatrização e o estabelecimento do tecido de granulação, seguido de epitelização. Registra-se que neste experimento a proliferação epitelial esteve presente em todos os grupos, particularmente no grupo B3 de forma intensa.

\section{CONCLUSÕES}

Os resultados alcançados, quanto à resposta tecidual de feridas cutâneas de camundongos tratadas com pomada de óleo de pimenta longa, espécie Piper hispidinervum, nas concentrações de 1,25, 2,5 e $5 \%$ apresentaram proliferação epitelial superior ao grupo controle, sendo evidenciado no grupo tratado com a concentração de 2,5 $\%$, no tempo de oito dias.

Como observado conclui-se que o material foi capaz de acelerar o processo de reparação tecidual em camundongos, embora o tempo não fosse suficiente para uma avaliação da reparação tecidual completa.

Os animais tratados nas concentrações acima referidas, no $8^{\circ}$ e mais acentuadamente no $12^{\circ}$ dia, revelaram características de regressão quanto ao reparo de feridas. Sugerese a continuidade do trabalho na investigação e caracterização deste fato.

\section{REFERÊNCIAS}

\author{
ABRAMO, A. C. Análise biológica da \\ atuação da lâmina esponjosa de colágeno \\ heterólogo sobre o tecido de granulação. \\ 130 p. Tese (Doutorado em São Paulo: Escola \\ Paulista de Medicina - Universidade Federal \\ de São Paulo, 1990. 130 p. (Tese - \\ Doutorado)
}

BALBINO C. A. , PEREIRA. L. M. et.al. Mecanismos envolvidos na cicatrização: uma revisão. Revista Brasileira de Ciências Farmacêuticas. São Paulo, v. 41, n.1, p. 27$51,2005$.

BARBUDO, G. R. , BELLETTI, M. E., EURIDES D. Reparação de feridas cutâneas de roedores da espécie Calimy callosus, 
tratadas com hidrocarboneto alifático; aspectos morfométricos, morfológicos e histológicos. Brazilian Journal of Veterinary Research and Animal Science. São Paulo, v. 38, n. 2, p. 62-68, 2001.

BARREIRO, E. J.; FRAGA, C. M. A utilização do safrol, principal componente químico do óleo de sassafráz, na síntese de substâncias bioativas na cascata do ácido araquidônio. 5 ed. São Paulo: . v. 22. 1999

BRITO, N. M. B. Aspectos morfológicos e morfométricos da cicatrização de feridas cutâneas abertas em ratos tratados com óleo de copaíba. São Paulo. Escola Paulista de Medicina, Universidade Federal de São Paulo, 1996. 56 p. (Dissertação - Mestrado).

CLARK, R. A. Regulation of fibroplasia in cutaneous wound repair. The American Journal of the Medical Sciences. Charleston, v. 306, p. 42-48, 1993.

CORRÊA JÚNIOR, C.; MING, L. C.; SCHEFFER, M. C. Cultivo de plantas medicinais, condimentares e aromáricas. $2^{\mathrm{a}}$ Ed. Jaboticabal: FUNEP, 1994. 162 p.

CORRÊA, M. P. Dicionário das plantas úteis do Brasil e das exóticas cultivadas. Rio de Janeiro: Imprensa Nacional, 1984. v. 3, p. 267-269.

COSTA, A. F. Farmacognosia. Lisboa. 2002. $1031 \mathrm{p}$.

COSTA, P. R. R. Safrol e eugenol: estudo da reatividade química e uso em síntese de produtos naturais biologicamente ativos $e$ seus derivados. Rio de Janeiro:Núcleo de Pesquisas de Produtos Naturais - Centro de Ciências da Saúde - UFRJ, 1999. p. 357-369.

COTRAN, R. S.; KUMAR, V.; ROBBINS, S. L. Robbins patologia estrutural e funcional. $4^{\mathrm{a}}$ Ed. Rio de Janeiro: Guanabara Koogan, 1989. $1231 \mathrm{p}$.

DIPIETRO, L. A.; REINTJES, M. G.; LOW, Q. E.; LEVI, B.; GAMELLI, R. L.

Modulation of macrophage recruitment into

Revista da Universidade Vale do Rio Verde, Três Corações, v. 9, n. 1, p. 258-276, jan./jul. 2011 wounds by monocyte chemo attractant protein-1. Wound Repair Regen., v. 9, p. 28-33, 2001.

EURIDES, D.; MAZZANTI, A. Aspectos morfológicos,morfométricos e histológicos da reparação tecidual de feridas cutâneas de camundongos tratadas com óleo de copaíba (Copaifera langsdorfii). Estudo Experimental. Uberlândia: Curso de Medicina Veterinária, 1995. 11 p.

EURIDES, D.; MAZZANTI, A. Morfologia e morfometria da reparação tecidual de feridas cutâneas de camundongos tratados com solução aquosa de barbatimão. Revista da Faculdade de Zootecnia, Veterinária e Agronomia. Uruguaiana, v. 2, n.1, p. 35-40, 1996.

GALINDO, A. S.; Actividad antimicrobiana "in vitro" de angiosperma colombiana. Universidade Nacional de Colômbia, Santa Fé de Bogotá, Colômbia, 1997

GOTTLIED, O. R.; KOKETSU, M.; MAGALHÃES; MAIA, M. T; MENDES, A. J. G. S. Óleos Essenciais da Amazônia. 1981. v.11. p.143-148.

GUIDUGLI-NETO, J. The effect of roentgen radiation on the capillary sprontsonal superficial loops of granulation tissue II: ultrastructural aspects. Revista de Odontologia da Universidade de São Paulo. São Paulo, v. 6, p. 66-71, 1992.

HAMRICK, J. L. Distribuition of genetic whitin and among natural florest population. In CHAMBERS, S.M.; MACBIDE, B \& THOMAS, W.L. 1982.

HIRAMATSU, K., CUI, L., KURODA . The emergence and evolution of methicillinresistant Staphilococcus aureus. Trends in Microbiology. London, v. 9, p. 486-493, 2001.

JUNQUEIRA, L. C.; CARNEIRO, J. Histologia Básica. 10 ed. Rio de Janeiro: Guanabara Koogan, 2004. 488 p. 
KLEIN, R. M. Ecologia da flora e vegetação do Vale do Itajaí. Sellowia. Iajaí, v. 32, 1980, p.165-389.

KNIGHT, KENNETHL L. Crioterapia no Tratamento das Lesões Esportivas. Ed. $5^{\text {a }}$ São Paulo: Ed Manote, 2000.

LACAZ, C. S. Antibióticos. São Paulo: E. Blucher, 1975. p. 395 - 402

LEFKOVITS, J; PLOW, E. F.; TOPOL, E. J. Platelet glycoprotein IIb/IIIa receptors in cardiovascular medicine. The New England Journal of Medicine. Massachusetts, v. 332, p. 1553-1559, 1995.

LITTER. M. Farmacologia. $3^{\mathrm{a}}$ Ed. Buenos Aires: Ateneo, 1966. p. 208 - 220

MAIA, J. G.; SILVA, M. L.; LUZ, A. I. R.; ZOGHBI, M. G. B.; RAMOS, L. S. Espécies de Piper da Amazônia ricas em safrol.

Química Nova. São Paulo, v. 10, n. 3, p. 200204, 1987.

MARTINS, E. R.; DE CASTRO, D. M.; CASTELLLANI, D. C.; DIAS, J. E. Plantas Medicinais. Viçosa: Universidade Federal de Viçosa, 1995. 220 p.

MIRANDA, E M. O Potencial de Manejo de Populações Nativas de Pimenta Longa Piper hispidinervum em Áreas de Reserva Extrativista. Acre: EMBRAPA, 2000. p 45 56.

NASSRI, M. R. G., Estudo comprativo "in vivo" da resposta tecidual quanto ao uso de diferentes materiais obturadores em endodontia. Universidade de Ribeirão Preto, São Paulo, 2002.

PEREIRA, M. S. V. Staphylococus aureus: O Microvilão da Resistência a Antibióticos. Departamento de Biologia Molecular, Universidade Federal de Pernambuco. Disponível em <http://www.biologianaweb> Acesso em: Jan de 2002.
PEREIRA, M. S. V. Atividade in vitro de Fluorquinolonas e ação sobre plasmídeos em amostras de Staphylococcus aureus humanas e bovinas. Universidade Federal de Pernambuco, Recife, 2000. 135 p. (Tese Doutorado).

PIMENTEL, F.; S, M. M. M.; SÁ, C. P. Recomendações Básicas para o Cultivo da Pimenta Longa Piper hispidinervum no Estado do Acre. Acre: EMBRAPA, dez., 1998.

PIMENTEL, F. A; PACHECO, E. P.; SILVA,M. R., Recomendações Básicas sobre colheita e secagem de biomassa triturada de Pimenta Longa ( Piper hispidinervum). Rio Branco: Embrapa Acre, 2000, p.1-3. (Embrapa Acre. Comunicado Técnico, 121)

PIÑA-RODRIGUES, F. C. M.; COSTA, L. G.; REIS, A. Estratégias para o estabelecimento de espécies arbóreas e o manejo de florestas tropicais. Campos do Jordão, 1989. p. 676-684.

PRATA, M. G.; HADDAD, C. M.; GOLDEMBERG, G. S. Uso tópico do açúcar em feridas cutâneas: estudo experimental em ratos. Acta Cirurgica Brasileira. São Paulo, v. 3, n. 2, p. 43-48, 1988.

RIZZI, C. T.; MORS, W. B. Botânica econômica brasileira. São Paulo: EPU, 1971. p 207 - 219.

ROBBINS, S. L.; Patologia estrutural e funcional. $4^{\mathrm{a}} \mathrm{Ed}$. Rio de Janeiro: Guanabara Koogan, 1991. 1231

ROCHA-NETO, O. G.; OLIVEIRA, J. R.; CARVALHO, J. E. U.; LAMERA, O. A.

Principais produtos extrativos da Amazônia e seus coeficientes técnicos.

Brasília: IBAMA, Centro de

Desenvolvimento Sustentado das Populações Tradicionais, $1999.78 \mathrm{p}$.

RUDOLPH, R.; BALLANTYNE, J. R.; ?, D. L. Skin grafts. In: McCARTHY, J. G.; MAY JR., J. W.; LITTLER, J. W. Plastic surgery. 
v. 1, p. 221-267. Philadelphia: WB Saunders, 1990.

SANCHEZ NETO, R.; BARONE, B.;

TEVES, D. C.; et al. Aspectos morfológicos e morfométricos da reparação tecidual de feridas cutâneas de ratos com e sem tratamento com solução de papaína a 2\%. Acta. Cir. Bras., v. 8, n. 1, p. 18-23, 1993.

SILVA, A.C.P.R.da \& OLIVEIRA, M.N. Caracterização botânica e química de três espécies do gênero Piper no Acre. Rio Branco: Embrapa Acre, 2000

.13p. (Embrapa Acre. Boletim de Pesquisa, 23)

SILVA, M. H. L. Tecnologia e produção racional de pimenta longa Piper hispidinervum C. DC. Universidade Federal do Rio de Janeiro, 1993. 120 p. (Tese -

Mestrado).

SHUKLA, A; RASIK, A. M; JAIN, G. K; In vitro and in vivo wound healing activity of asiticodide isolated from Centelha asiatica. Journal of Ethnopharmacology. v. 65, p. 0378-8741. 1998.

SIMÕES, C. M. O.; SHENKEL, E. P.; GOSMANN, G. Farmacognosia da Planta ao Medicamento. 3 ed. UFRGS: 2001.

SUASSUNA, I. Interpretação clínica de antibiograma. 1974. p. 38-50

SUFFREDINI, I. B.; SADER H. S.; GONÇALVES, G; Screening of antibacterial extracts from plants native to the brazilian amazon rain forest and atantic forest. v. 3, p. 379-384, 2004.

VIEIRA, S. Introdução à Bioestatística. Rio de Janeiro: , 1998. 196p.

VONYUNCKER, T. G. The Piperaceae of Brazil.São Paulo: Instituto de Botânica.1972.p.
VON KOSSEL, K. Gangliosideos - estudo do colágeno e da resposta inflamatória no. 